\title{
Regulation of retinoic acid synthetic enzymes by WT1 and HDAC inhibitors in 293 cells
}

\author{
YIFAN LI ${ }^{1,2}$, LEI WANG ${ }^{1}$, WEIPENG AI ${ }^{3}$, NIANHUI HE ${ }^{3}$, LIN ZHANG $^{7}$, JIHUI DU $^{1}$, YONG WANG $^{4}$, \\ XINGJIAN MAO ${ }^{1}$, JUNQI REN ${ }^{5}$, DAN XU $^{6}$, BEI ZHOU $^{1}$, RONG LI $^{1}$ and LIWEN MAI ${ }^{1}$ \\ ${ }^{1}$ Central Laboratory, ${ }^{2}$ Shenzhen Key Laboratory of Endogenous Infection, and Departments of ${ }^{3}$ Clinical Pharmacology, \\ ${ }^{4}$ Gastroenterology, ${ }^{5}$ Pathology and ${ }^{6}$ Clinical Laboratory, Shenzhen Nanshan People's Hospital/Affiliated \\ Shenzhen Sixth Hospital of Guangdong Medical University, Shenzhen, Guangdong 518052; \\ ${ }^{7}$ Institute of Digestive Diseases and State Key Laboratory of Digestive Diseases, \\ LKS Institute of Health Sciences and Department of Medicine and Therapeutics, \\ Faculty of Medicine, Chinese University of Hong Kong, Hong Kong SAR, P.R. China
}

Received May 21, 2016; Accepted June 21, 2017

DOI: 10.3892/ijmm.2017.3051

\begin{abstract}
All-trans retinoic acid (atRA), which is mainly generated endogenously via two steps of oxidation from vitamin A (retinol), plays an indispensible role in the development of the kidney and many other organs. Enzymes that catalyze the oxidation of retinol to generate atRA, including aldehyde dehydrogenase 1 family (ALDH1)A1, ALDH1A2 and ALDH1A3, exhibit complex expression patterns at different stages of renal development. However, molecular triggers that control these differential expression levels are poorly understood. In this study, we provide in vitro evidence to demonstrate that Wilms tumor 1 (WT1) negatively regulates the expression of the atRA synthetic enzymes, $A L D H 1 A 1, A L D H 1 A 2$ and $A L D H 1 A 3$, in the 293 cell line, leading to significant blockage of atRA production. Furthermore, we demonstrate that the suppression of ALDHIAI by WT1 can be markedly attenuated by histone deacetylase inhibitors (HDACis). Taken together, we provide evidence to indicate that WT1 and HDACs are strong regulators of endogenous retinoic acid synthetic enzymes in 293 cells, indicating that they may be involved in the regulation of atRA synthesis.
\end{abstract}

\section{Introduction}

All-trans retinoic acid (atRA) is a chemical essential for the regulation of a wide range of biological processes, such as organ development (1), regeneration, differentiation (2) and cancer (3). It acts as a ligand for nuclear retinoic acid recep-

Correspondence to: Dr Yifan Li, Central Laboratory, Shenzhen Nanshan People's Hospital/Affiliated Shenzhen Sixth Hospital of Guangdong Medical University, 89 Taoyuan Road, Shenzhen, Guangdong 518052, P.R. China

E-mail: liyifan2005@yahoo.com

Key words: retinoic acid, Wilms' tumor 1, aldehyde dehydrogenase 1 family, member A1, 293 cells, histone deacetylase inhibitors tors (RARs), which includes $\operatorname{RAR} \alpha, \operatorname{RAR} \beta$ and $\operatorname{RAR} \gamma$, leading to the alteration of gene transcription and subsequent biological processes (4). Endogenous atRA is generated via two steps of oxidation of vitamin A (all-trans retinol), through an intermediate state, all-trans retinal $(1,5)$. The second and irreversible step of retinoic acid synthesis is catalyzed by enzymes, including aldehyde dehydrogenase 1 family (ALDH1)A1 (6), ALDH1A2 (7,8) and ALDH1A3 (9,10) (Fig. 1A).

The embryonic kidney develops through reciprocal induction between the ureteric bud branched from the Wolffian duct and its surrounding mesenchyme, which both derive from the intermediate mesoderm. Wolffian duct extends caudally and interacts with its adjacent mesenchyme to form pronephros, mesonephros and metanephros. The former two structures are transient, while the latter structure metanephros develops to form kidney seen in adult. Metanephric mesenchyme is induced to form condensed mesenchyme (cap mesenchyme) and then differentiates into different linages, including epithelial cells (through sequential structures including pretubular aggregate, renal vesicle, comma- and S-shaped bodies, and renal nephrons, including podocytes on the renal vesicle layer of the glomerulus, proximal convoluted tubule, loop of Henle and distal convoluted tubule), stromal cells and endothelial cells. Ureteric buds differentiate into the collecting duct, renal calyces, pelvis and ureter $(11,12)$.

Retinoic acid signaling is absolutely essential for renal development, which has been shown by the double knockout of $R A R \alpha / \beta 2$, that leads to hypoplasia/agenesis of the kidney (13). To date, one of the major pathways mediating the effect of retinoic acid on renal development is the upregulation of ret proto-oncogene (Ret) expressed on the cell membrane of the ureter bud, which binds its ligand glial cell line derived neurotrophic factor $(G d n f)$ secreted from the differentiating mesenchyme $(14,15)$. Retinoic acid synthesis, the upstream regulatory point of retinoic acid signaling, is also critical for renal development, demonstrated by Aldhla2 $2^{-/-}$mutant mouse kidneys that exhibit a significant reduction in ureteric buds and nephrons, and Aldhla2 $2^{-/ / A l d h l a 3^{-/}}$mutant kidneys that exhibit 
a more severe pattern of abnormities (14). However, it has also been shown that excessive retinoic acid can be teratogenic and an cause hypoplastic and polycystic kidneys (16). These data suggest that the deficiency or excess of retinoic acid signaling results in abnormalities in renal development.

Furthermore, the timely and precise 'turning on and off' of atRA production in specific zones of the developing kidney is also critical. atRA, one of the major secreted signaling molecules, contributes to the complex dynamics of epithelial cell branching morphogenesis and nephron patterning (11). For example, evidence indicates that retinoic acid controls the positioning and segmentation of zebrafish pronephros (17). Studies on the development of the hindbrain (18-20), paraxial mesoderm (21), and limb (22), suggest that atRA acts in a diffusion (morphogen-like) gradient pattern to drive proper cell differentiation and patterning in development. This pattern may also be applied to renal development (21), by tightly control of retinoic acid degradation enzymes CYP26 $(18,19)$, or specific retinoic acid synthetic enzymes.

The retinoic acid synthetic enzymes Aldhlal, Aldhla2 and Aldhla3 display a dynamic and complex expression pattern in the course of kidney organogenesis and nephron differentiation. Aldhlal and Aldhla3 are predominantly expressed in differentiating tubular structures derived from S-shaped bodies or developing structure derived from the ureter bud. The expression levels of Aldhlal and Aldhla3 are not detectable at different stages in the cell lineage that differentiates into podocytes (14,23-25). Aldhla2 expression is mainly stromal. It is also weakly expressed in the proximal segment of comma-shaped body, and strongly, but transiently expressed in the glomerular anlagen in S-shaped body and visceral layer of glomerulus in the stage III nephron, which then decreases sharply in podocytes of the stage IV nephron. During E18-P4, it is also expressed in collecting tubules $(14,15,24,25)$. The absence of Aldhlal and Aldhla3 expression at different stages in the cell linage that finally forms podocytes, together with the downregulation of Aldhla 2 in podocytes, suggests that not yet identified regulators may negatively regulate their expression in this developing stem/progenitor cell population.

Wilms' tumor 1 (WT1) encodes a transcription factor that can either upregulate or downregulate the expression of the same gene in a different cellular context, which may be largely due to the effects of its co-factors $(26,27)$ and the "chromatin flip-flop' effect that involves CCCTC-binding factor (zinc finger protein) (CTCF) and the protein complex cohesin for maintenance of the chromatin insulating boundaries (28). WT1 has four major isoforms arising from alternative splicing by combinatorial insertions of exon 5 and lysine, threonine and serine (KTS) at the end of exon 9 (29), in which the WT1(+/-) isoform (with exon 5, without KTS) primarily acts as a transcription factor (30). WT1 expression begins on embryonic day 9.5 (E9.5) within the urogenital ridge in mice. During renal development, WT1 is lowly expressed in the uninduced metanephric blastema, then it is limited in and increases progressively in the condensed mesenchyme, renal vesicle, comma- and S-shaped bodies, and glomerular podocyte $(31,32)$. Wtl is not expressed in the ureteric bud and its derivatives (31). WT1 is one of the major regulators of normal kidney development, demonstrated by evidence that the Wtl gene knockout leads to agenesis of the kidney in mice (33).
Previous studies have suggested that $\mathrm{Wt} 1$ is a positive regulator of Aldhla2 and Aldhlal expression in the development of the heart, liver and gonad. Wt1 null mice exhibit the downregulation of Aldhla2 in the developing epicardium (34,35). It was later shown that Wt1 directly upregulates Aldhla2 expression in the embryonic epicardium (36). Coelomic cells lining the liver in the Wt1 null embryo exhibit a decrease or absence of Aldhla2 expression (35). The Wtl null mouse embryo exhibits the loss of Aldhlal expression in the gonad (37), indicating that Wt1 may positively regulate Aldhlal expression in the gonad. However, although Wt1 knockout is associated with the decreased expression of Aldhlal in the developing gonad; the same study also showed that Aldhlal was not expressed in the differentiating renal vesicle lineage (37), where $W t 1$ is increasingly expressed $(31,32)$. In the developing kidney, it has been reported that Aldh1a2 mRNA expression is strong in the mouse mesenchyme at E11 (7), where Wt1 expression is just beginning. Aldhla 2 is later strongly expressed in the presumptive podocytes, but its expression decreases markedly in more differentiated podocytes of the stage IV nephron (25), in which $W t 1$ is strongly expressed $(31,32)$.

Thus, the rationales for this study are the following: i) Aldhlal and Aldhla3 expression are negatively associated with Wt1 expression during renal development; ii) Aldhla 2 is downregulated in podocytes of the stage IV nephron where WTI expression is progressively increased; iii) WT1 is a positive regulator of Aldhla2 and Aldhlal expression in other organ development, but it can regulate the same gene in both directions. Therefore, we propose that WT1 may negatively regulate Aldhlal, Aldhla2 and Aldhla3 expression. In this study, we demonstrate that $A L D H 1 A 2$ and $A L D H 1 A 3$ are both highly expressed in 293 cells. We demonstrate that WT1 represses the expression of $A L D H 1 A 1, A L D H 1 A 2$ and $A L D H 1 A 3$, leading to the significant inhibition of retinoic acid synthesis in 293 cells. We further demonstrate that the repression of $A L D H 1 A 1$ by WT1 can be alleviated by histone deacetylase (HDAC) inhibitors, which are potent regulators of kidney development and disease $(38,39)$.

\section{Materials and methods}

Chemicals. 5-Aza-2'-deoxycytidine (AZA) (A3656), which is an epigenetic modifier resulting in DNA demethylation (hypomethylation) and gene activation, was obtained from Sigma (St. Louis, MO, USA). The HDAC inhibitors, MS-275 (13284), Chidamide (13686) and SAHA (10009929), were from Cayman (Ann Arbor, MI, USA). They were all dissolved in DMSO (MP Biomedicals, Santa Ana, CA, USA) at a concentration of $10 \mathrm{mmol} / \mathrm{l}$. MS-275 and chidamide belong to the benzamide-type HDAC inhibitor, which mainly inhibits class I HDACs (including HDAC1, HDAC2 and HDAC3). MS-275 at $5 \mu \mathrm{mol}$ primarily inhibits HDAC1 and HDAC3 (40). The chemical structure of chidamide is highly similar to that of benzamide MS-275. Chidamide has been previously shown to increase histone $\mathrm{H} 3$ acetylation in colon cancer cells at $4 \mu \mathrm{mol} / 1$ (41). SAHA belongs to the hydroxamate type HDAC inhibitors and can inhibit class I and II HDACs at $5 \mu \mathrm{mol} / 1$ (42). All-trans retinol (R7632), all-trans retinal (R2500), all-trans retinoic acid (R2625) and retinyl acetate (46958) were from Sigma, and all were prepared in DMSO at a concentration of $50 \mathrm{mmol} / \mathrm{l}$. 
Table I. Sequences of primers used for RT-qPCR.

\begin{tabular}{lll}
\hline $\begin{array}{l}\text { Genes } \\
\text { detected }\end{array}$ & \multicolumn{1}{c}{$\begin{array}{c}\text { Primer } \\
\text { names }\end{array}$} & \multicolumn{1}{c}{$\begin{array}{c}\text { Primer sequences } \\
\text { (5' to 3') }\end{array}$} \\
\hline WT1 & $\begin{array}{l}\text { WT1-RQF } \\
\text { WT1-RQR }\end{array}$ & $\begin{array}{l}\text { CCAGCCCGCTATTCGCAATCA } \\
\text { CTCATGCTTGAATGAGTGGTTGGG }\end{array}$ \\
AREG & AREG-RQF & GCACCTGGAAGCAGTAACATGCAA \\
& AREG-RQR & GATCACAGCAGACATAAAGGCAGC \\
ALDH1A1 & ALDH1A1-QF2 & ACTGCTCTCCACGTGGCATCTTTA \\
& ALDH1A1-QR2 & TGCCAACCTCTGTGATCCTGTGA \\
ALDH1A2 & ALDH1A2-QF2 & GGGCAGTTCTTGCAACCATGGAAT \\
& ALDH1A2-QF2 & TTTGATGACGCCCTGCAAATCCAC \\
ALDH1A3 & ALDH1A3-QF1 & GCATGAGCCCATTGGTGTCT \\
& ALDH1A3-QR1 & CGCAGGCTTCAGGACCAT \\
ALDH8A1 & ALDH8A1-QF1 & AAAGTCGGCATTCCCTCTGATCCA \\
& ALDH8A1-QR1 & ACCGTGGGAAGCATAAAGTAGCCT \\
TBP & TBPRQF & GCCCGAAACGCCGAATAT \\
& TBPRQR & CCGTGGTTCGTGGCTCTCT \\
\hline
\end{tabular}

WT1, Wilms' tumor 1; AREG, amphiregulin; $A L D H 1$, aldehyde dehydrogenase 1 family; $T B P$, TATA box binding.

Primers. The sequences of primers for reverse transcriptionquantitative PCR (RT-qPCR) and bisulfite PCR used in this study are listed in Tables I and II, respectively.

Plasmids. The WT1(+/-) isoform was originally cloned from a normal Chinese liver tissue. WT1(+/-) cDNA was cloned into the pcDNA3.1(+) vector using EcoRI/NotI restriction enzyme sites, resulting in the pcDNA3.1-WT1 vector. The human ALDH1A2 mammalian expression vector, pReceiver-M67-ALDH1A2, and the negative control, pReceiver-M67 empty vector, were purchased from GeneCopoeia (Guangzhou, China). Open reading frame sequences of these vectors were confirmed by dideoxy sequencing at BGI Tech (Guangzhou, China).

Cell culture and transfection. The 293 cells (adenovirus transformed cells) (43) were obtained from the Cell Bank of Type Culture Collection of Chinese Academy of Sciences (Shanghai, China) (WFCC registered no. 793). The WiT49 cells were kindly provided by Dr Herman Yeger. It is a Wilms' tumor (WT) cell line derived from the first-generation xenograft of a human WT lung metastasis (44). The 293 cells were cultured in Dulbecco's modified Eagle's medium (DMEM) (HyClone, Logan, UT, USA) supplemented with $10 \%$ fetal bovine serum (FBS) (Gibco, Grand Island,NY,USA), 2 mmol/lL-glutamine(Sigma), $100 \mathrm{U} / \mathrm{ml}$ penicillin and $100 \mu \mathrm{g} / \mathrm{ml}$ streptomycin (Gibco). The WiT49 cells were cultured in DMEM supplemented with 15\% FBS (Gibco), $2 \mathrm{mmol} / \mathrm{l} \mathrm{L}$-glutamine (Sigma), $100 \mathrm{U} / \mathrm{ml}$ penicillin, $100 \mu \mathrm{g} /$ $\mathrm{ml}$ streptomycin (Gibco), $0.5 \mathrm{ml} / 500 \mathrm{ml}$ 2-mercaptoethanol $(\mathrm{x} 1,000)$ (Invitrogen, Carlsbad, CA, USA) and $6 \mathrm{mg} / 500 \mathrm{ml}$ insulin (44). The pcDNA3.1-WT1 or the control vector pcDNA3.1 (Invitrogen) was transfected into the 293 cells in a 6-well plate separately at an amount of $1 \mu \mathrm{g} /$ well using FuGENE ${ }^{\circledR}$ HD Transfection Reagent (Promega, Madison, WI, USA). The 293 cells that were transfected with pcDNA3.1-WT1 or pcDNA3.1 were selected using $800 \mu \mathrm{g} / \mathrm{ml} \mathrm{G} 418$ (Amresco,
Solon, OH, USA) for a week, resulting in cells named 293pc and 293pcWT1, respectively. The 293pcWT1 cells were further subcloned and 293pcWT1-9 and 293pcWT1-69 cell lines with high $W T 1$ expression were used in the rest of the experiments.

Cell treatment. 293pcWT1-9 and 293pcWT1-69 cells were treated with AZA at a final concentration of $5 \mu \mathrm{mol} / 1$ or the solvent DMSO as a negative control for 48 and 72 h. 293pc, 293pcWT1-9 and 293pcWT1-69 cells were treated with chidamide, MS-275 and SAHA, each at a final concentration of $5 \mu \mathrm{mol} / 1$, for 24,48 or $72 \mathrm{~h}$, respectively, along with their solvent DMSO control.

$R T-q P C R$. RNA was extracted using TRIzol reagent (Invitrogen) and its concentration and purity were measured at 260/280 nm using a NanoDrop spectrophometer (Thermo Thermo Fisher Scientific, Waltham, MA, USA). Total RNA $(1 \mu \mathrm{g})$ was reverse-transcribed with oligo(dT $)_{20}$ at $50^{\circ} \mathrm{C}$ for $1 \mathrm{~h}$ using the ThermoScript RT-PCR system (Invitrogen). Comparative quantitative (real-time) PCR was performed using SYBRGreen qPCR SuperMix universal (Invitrogen) on ABI 7500 Fast Real-Time PCR System (Applied Biosystems, Foster City, CA, USA). The reaction mixture was composed of $10 \mu \mathrm{l}$ Fast SYBR-Green Master Mix (Invitrogen), $50 \mathrm{nmol} / \mathrm{l}$ ROX reference dye, $0.2 \mu \mathrm{mol} / 1$ forward primer, $0.2 \mu \mathrm{mol} / 1$ reverse primer and $5 \mu \mathrm{l}$ of 1:10 diluted cDNA template. PCR cycling was carried out as follows: $50^{\circ} \mathrm{C}$ for $2 \mathrm{~min}$, a denaturation step of $95^{\circ} \mathrm{C}$ for $10 \mathrm{~min}$, followed by 40 cycles of $95^{\circ} \mathrm{C}$ for $15 \mathrm{sec}, 58^{\circ} \mathrm{C}$ for $30 \mathrm{sec}$ and $72^{\circ} \mathrm{C}$ for $30 \mathrm{sec}$. Gene expression levels were quantified using the comparative $\mathrm{Ct}$ method, normalizing to the housekeeping gene, TATA box binding protein $(T B P)$. Assays were carried out in duplicate.

Western blot analysis. Western blot analysis was carried out using antibodies to WT1 C19, $\beta$-actin C4 (both from Santa Cruz Biotechnology, Inc., Santa Cruz, CA, USA), glyceraldehyde 3-phosphate dehydrogenase (GAPDH) (Goodhere, Hangzhou, China), ALDH1A1, ALDH1A2 and ALDH1A3 (all from Abcam, Cambridge, UK). Secondary antibodies, including anti-rabbit IgG (whole molecule)-peroxidase antibody and anti-mouse IgG (whole molecule)-peroxidase antibody, were from Sigma. Briefly, $1 \times 10^{6}$ cells were lysed in $150 \mu 11 \mathrm{X}$ cell lysis buffer (Cell Signaling Technology, Beverly, MA, USA), plus EDTA-free protease inhibitor cocktail (Roche, Indianapolis, IN, USA). Protein concentrations were determined using the DC Protein assay kit (Bio-Rad, Hercules, CA, USA). For each lane, $30 \mu \mathrm{g}$ proteins were lysed in $30 \mu \mathrm{l}$ sample buffer [60 mmol/1 Tris pH 6.8, 10\% glycerol, 2\% sodium dodecyl sulfate (SDS), $5 \%$ mercaptoethanol], followed by incubation at $100^{\circ} \mathrm{C}$ for $5 \mathrm{~min}$ and cooling on ice to denature proteins. Protein samples were loaded for electrophoresis and transferred onto Immobilon-P transfer membranes (Millipore, Billerica, MA, USA) with a wet transfer apparatus (Bio-Rad). The Immobilon-P membranes were blocked with $1 \%$ bovine serum albumin (BSA) (Sigma) in phosphate-buffered saline (PBS) for $2 \mathrm{~h}$ at room temperature. The membranes were then probed with primary antibodies overnight at $4^{\circ} \mathrm{C}$ at a dilution of 1:200 or 1:1,000, followed by incubation with secondary antibody at room temperature for $1.5 \mathrm{~h}$. Protein bands were visualized with ECL $^{\mathrm{TM}}$ Prime Western Blotting detection reagent (Amersham, 
Table II. Sequences of primers used for PCR.

\begin{tabular}{|c|c|c|}
\hline $\begin{array}{l}\text { Bisulfite PCR } \\
\text { fragment labels }\end{array}$ & Primer names & $\begin{array}{l}\text { Primer sequences } \\
\quad\left(5^{\prime} \text { to } 3^{\prime}\right)\end{array}$ \\
\hline ALDH1A1 BS1 & $\begin{array}{l}\text { ALDH1A1-BSF1 } \\
\text { ALDH1A1-BSR1 }\end{array}$ & $\begin{array}{l}\text { ATGTTGGAGTATTGGTTTTTTAAGG } \\
\text { TCAAAACAAAAAATAAAAATTTTACTCAC }\end{array}$ \\
\hline ALDH1A2 BS0 & $\begin{array}{l}\text { ALDH1A2-BSF0 } \\
\text { ALDH1A2-BSR0 }\end{array}$ & $\begin{array}{l}\text { AGTTTGAGTGAAGGAGTGAGATTTT } \\
\text { CCAAACCTTAAACTCATTTTACTATCC }\end{array}$ \\
\hline ALDH1A2 BS1 & $\begin{array}{l}\text { ALDH1A2-BSF1 } \\
\text { ALDH1A2-BSR1 }\end{array}$ & $\begin{array}{l}\text { ATAGTAAAATGAGTTTAAGGTTTGG } \\
\text { AAAAAACCAAAAAAATCCAAACTAC }\end{array}$ \\
\hline ALDH1A2 BS2 & $\begin{array}{l}\text { ALDH1A2-BSF2 } \\
\text { ALDH1A2-BSR2 }\end{array}$ & $\begin{array}{l}\text { GTAGTTTGGATTTTTTTGGTTTTTT } \\
\text { CAAACTAAAACTCTTCTTATTAAAC }\end{array}$ \\
\hline ALDH1A2 BS3 & $\begin{array}{l}\text { ALDH1A2-BSF3 } \\
\text { ALDH1A2-BSR3 }\end{array}$ & $\begin{array}{l}\text { TTTAGTTTGATATTTGTTTATATATAGG } \\
\text { AACAAACAAAAAATCCCTCTACTAC }\end{array}$ \\
\hline ALDH1A3 BS1 & $\begin{array}{l}\text { ALDH1A3-BSF1 } \\
\text { ALDH1A3-BSR1 }\end{array}$ & $\begin{array}{l}\text { AGTAGTAAAGGTTTTATGTGTTTTTT } \\
\text { TACCCTACTCTTAAATCCAACC }\end{array}$ \\
\hline ALDH1A3 BS2.1 & $\begin{array}{l}\text { ALDH1A3-BSF2 } \\
\text { ALDH1A3-BSR2-2 }\end{array}$ & $\begin{array}{l}\text { GGTTGGATTTAAGAGTAGGGTA } \\
\text { CACCTTAATAAACTTAACCTCCAA }\end{array}$ \\
\hline ALDH1A3 BS2.2 & $\begin{array}{l}\text { ALDH1A3-BSF2-TG2 } \\
\text { ALDH1A3-BSF2-CG2 } \\
\text { ALDH1A3-BSR2 }\end{array}$ & $\begin{array}{l}\text { GTTTATAGGTAGTTTTTGGGG } \\
\text { GTTTATAGGTAGTTTTCGGGG } \\
\text { TTAATAAACTTAACCTCCAAATTAC }\end{array}$ \\
\hline ALDH1A3 BS3 & $\begin{array}{l}\text { ALDH1A3-BSF3 } \\
\text { ALDH1A3-BSR3 }\end{array}$ & $\begin{array}{l}\text { GTAATTTGGAGGTTAAGTTTATTAA } \\
\text { AAAAAAACTCCCCAAAACCAA }\end{array}$ \\
\hline
\end{tabular}

$A L D H 1$, aldehyde dehydrogenase 1 family.

GE Healthcare, Buckinghamshire, UK). Images were acquired using the MiniChemi professional machine (SageCreation Science Co., Ltd., Beijing, China).

High-performance liquid chromatography (HPLC). Treatment of the cells and the extraction of retinoids were performed as previously described with some modifications $(45,46)$. Briefly, the cells were seeded in a $3 \times 10^{6} / \mathrm{T} 25$ flask in $5 \mathrm{ml}$ DMEM supplemented with $3 \%$ FBS. At $24 \mathrm{~h}$ post-seeding, the cells were incubated with $10 \mu \mathrm{mol} / \mathrm{l}$ all-trans retinal (Sigma) as a substrate for $4 \mathrm{~h}$. DMEM $(5 \mathrm{ml})$ was harvested to a disposable glass tube $(16 \times 150 \mathrm{~mm})$. The cells were then lysed with $530 \mathrm{ml} 1 \mathrm{X}$ SDS lysis buffer (Promega, Madison, WI, USA) and collected to the glass tube containing $5 \mathrm{ml}$ DMEM, followed by addition of $1 \mu 150 \mathrm{mmol} / \mathrm{l}$ retinol acetate in DMSO as an internal standard (IS) (47). Two mililiters $0.025 \mathrm{~mol} / 1 \mathrm{KOH}$ in ethanol was added and mixed. Subsequently, $4 \mathrm{ml}$ hexane were added and mixed thoroughly, followed by centrifugation at $1,500 \mathrm{rpm}$ for $5 \mathrm{~min}$ for phase separation. The hexane phase on the top layer which contains neutral lipids, retinol and retinyl esters was transferred to a new disposable glass tube. This was followed by the addition of $600 \mu \mathrm{l} 4 \mathrm{~mol} / \mathrm{l} \mathrm{HCL}$ to the original tube and mixed, and by the addition of $4 \mathrm{ml}$ of hexane and mixing thoroughly. The mixture was spun at 1,500 rpm for $5 \mathrm{~min}$. The hexane phase on the top layer containing retinoic acid was transferred and combined with the previous hexane phase. The hexane solvent from the first and second extraction was evaporated under a stream of nitrogen with heating at $30^{\circ} \mathrm{C}$ in the dark. Residues were dissolved in $1 \mathrm{ml}$ acetonitrile for each tube. Resuspended samples were analyzed immediately by HPLC using conditions as previously described $(47,48)$. Briefly, HPLC was carried out on the Shimadzu LC solution system with Inertsil ${ }^{\circledR}$ ODS-SP column $(5 \mu \mathrm{m}, 4.6 \times 150 \mathrm{~mm})$ and mobile phase comprising $30 \mathrm{mmol} / \mathrm{l}$ ammonium acetate/acetonitrile $(15: 85, \mathrm{v} / \mathrm{v})$. Retinoids were monitored at $340 \mathrm{~nm}$. The approximate retention times for atRA, retinol, retinal and retinyl esters were 3.9, 6.4, 7.7 and $10.9 \mathrm{~min}$ at a flow rate of $1 \mathrm{ml} / \mathrm{min}$. The recovery of atRA was determined to monitor extraction efficiency of atRA. The average recovery ( \pm SEM) of atRA is $80 \% \pm 2(n=3)$, at a similar level as reported previously (46).

Methylation analysis. Genomic DNA was bisulfite-converted using the EZ DNA Methylation-Gold kit ${ }^{\mathrm{TM}}$ (Zymo Research, Irvine, CA, USA). Bisulfite PCR was performed using the HotStarTaq Plus DNA polymerase (Qiagen, Hilden, Germany) on the PTC-200 Peltiler Thermal Cycler (Bio-Rad). PCR products were ligated to the pGEMT-Easy vector (Promega), followed by transformation into DH5 $\alpha$ E. coli competent cells. A total of 8-12 clones for each bisulfite PCR product were dideoxy sequenced at BGI Tech.

Software. Primers were designed using the PrimerQuest Design Tool (http:/www.idtdna.com/primerquest/Home/ Index). Primers for bisulfite PCR were designed using the MethPrimer program (49). Bisulfite sequencing figures were produced using CpGviewer software (50). Histograms were plotted using Microsoft Excel software (Microsoft, Redmond, WA, USA). The western blot analysis data were analyzed using ImageJ software (51). 

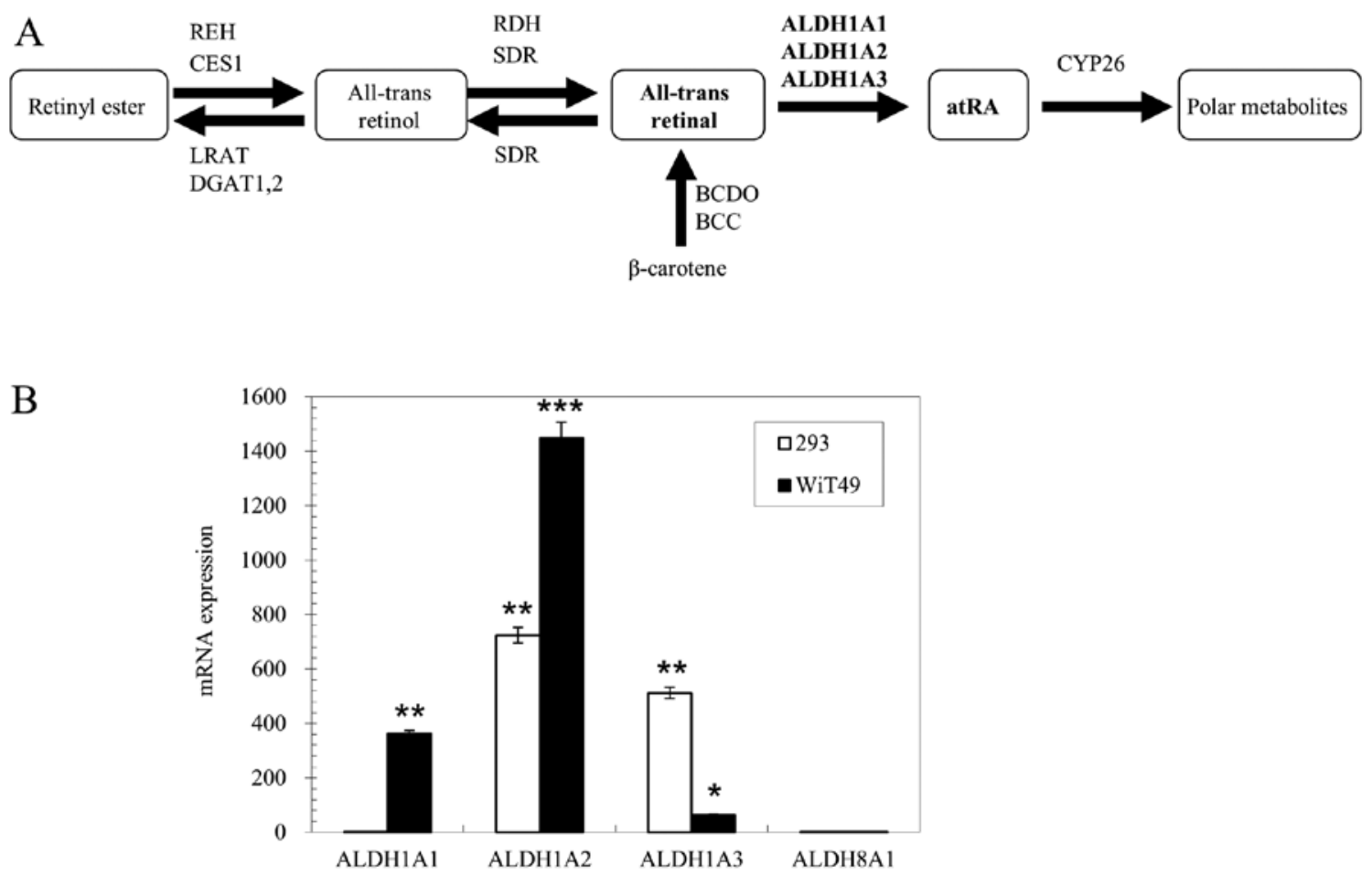

Figure 1. mRNA expression analysis of retinoic acid synthetic enzymes in 293 cells and WiT49 cells. (A) Pathway of retinoic acid synthesis and metabolism. (B) mRNA expression of ALDH1A1, ALDH1A2, ALDH1A3 and ALDH8A1 relative to house-keeping gene TBP in 293 and WiT49 cells measured by real-time PCR. Data are expressed as fold changes relative to ALDH1A1 expression in 293 cells. Results are representative of 3 separate experiments. Error bars show the range of duplicate measurements; primer sequences are shown in Table I. REH, retinyl ester hydrolase; CES1, carboxylesterase 1; LRAT, lecithin:retinol acyltransferase; DGAT, diacylglycerol acyltransferase; RDH, retinol dehydrogenase; SDR, short-chain dehydrogenase/reductase; ALDH1A1, aldehyde dehydrogenase 1 family, member A1; ALDH1A2, aldehyde dehydrogenase 1 family, member A2; ALDH1A3, aldehyde dehydrogenase 1 family, member A3; CYP26, cytochrome $\mathrm{P} 450$, family 26 ; BCDO, carotene- 15,15 '-dioxygenase; BCC, $\beta$-carotene cleavage enzyme. ${ }^{*} \mathrm{P}<0.05,{ }^{* *} \mathrm{P}<0.01$ and ${ }^{* * *} \mathrm{P}<0.001$ vs. ALDH1A1 expression level in the 293 cells, calculated using the Student's t-test.

Statistical analysis. Statistical analysis was performed using Microsoft Excel 2010 software (Microsoft). The Student's t-test was used to determine whether two sets of data were significantly different from each other. Representative data are expressed as the means \pm range of duplicate measurements from 3 independent experiments. A value of $\mathrm{P}<0.05$ was considered to indicate a statistically significant difference.

\section{Results}

Expression of ALDH1A1, ALDH1A2 and ALDH1A3 in 293 and WiT49 cells. WT arises from the developing kidney as the metanephric blastema fails to undergo its normal developmental pathway (52). The WT cell line, WiT49, has features of undifferentiated fetal kidney cells (44). Therefore, we performed RT-qPCR to examine the expression levels of $A L D H 1 A 1$, $A L D H 1 A 2$ and $A L D H 1 A 3$ in 293 and Wit49 cells. $A L D H 1 A 2$ and $A L D H 1 A 3$ were found to be highly expressed in the 293 cells, 724- and 512-fold higher compared to $A L D H 1 A 1$ expression, respectively. The $A L D H 1 A 1$ and $A L D H 8 A 1$ expression levels were both extremely low in the 293 cells. ALDH8Al expression was 2-fold higher compared to $A L D H 1 A 1$ expression in the 293 cells (Fig. 1B). The ALDH1A2, ALDH1A1 and ALDH1A3 expression levels in the WiT49 cells were relatively high, 1448-, 362- and 64-fold higher compared to ALDH1Al expression in the 293 cells, respectively. However, ALDH8Al expression in the WiT49 cells was also low, which was 0.5 -fold higher compared to ALDH1Al expression in the 293 cells (Fig. 1B). ALDH8A1 is a human analogue of mouse retinal dehydrogenase 4 (Raldh4), which can catalyze the synthesis of 9-cis-retinoic acid $(9,53)$ and 13-cis-retinoic acid (9).

Stable transfection of WT1 into 293 cells leads to the suppression of ALDH1A1, ALDHIA2 and ALDHIA3. Amphiregulin (AREG) has previously been shown to be a target of WT1 (54). In this study, in order to examine the effectiveness of pcDNA3.1-WT1 on gene regulation, this plasmid or its empty vector, pcDNA3.1, was transiently transfected into 293 cells, which were then cultured for 4 days. In the pcDNA3.1WT1-transfected 293 cells, as WT1 mRNA was upregulated 7,747-fold, AREG mRNA expression was upregulated 9.54fold, compared to that of the pcDNA3.1-tranfected 293 cells, as measured by RT-qPCR (Fig. 2A). The upregulation of WT1 protein in the pcDNA3.1-WT1-transfected 293 cells compared to the pcDNA3.1-tranfected 293 cells was also examined by western blot analysis (Fig. 2B).

Subsequently, the 293 cells transfected with pcDNA3.1 or pcDNA3.1-WT1 were selected with G418, resulting in 293pc and 293pcWT1 cells, respectively. The 293 cells transfected with pcDNA3.1-WT1 were then subcloned. Two subclones of the 293pcWT1 cells with a high expression of WT1, the 293pcWT1-9 and 293pcWT1-69 cell lines, were used in the subsequent experiments. RT-qPCR revealed that in the 293pcWT1-9 and 293pcWT1-69 cells, when WT1 was upregulated 46.3- and 85.9-fold, ALDH1A1, ALDH1A2, ALDH1A3 and ALDH8A1 were all suppressed to different levels, compared to those of 
A

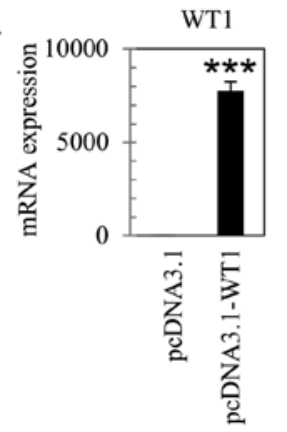

C

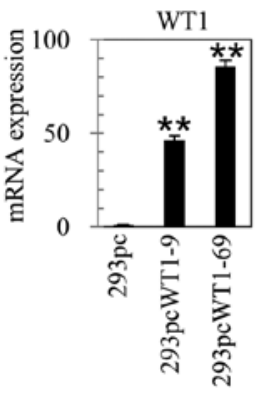

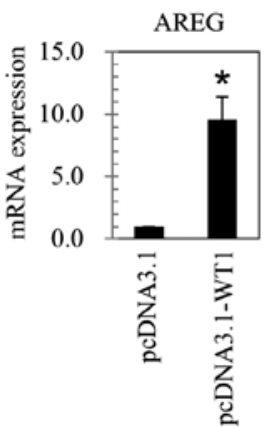

B
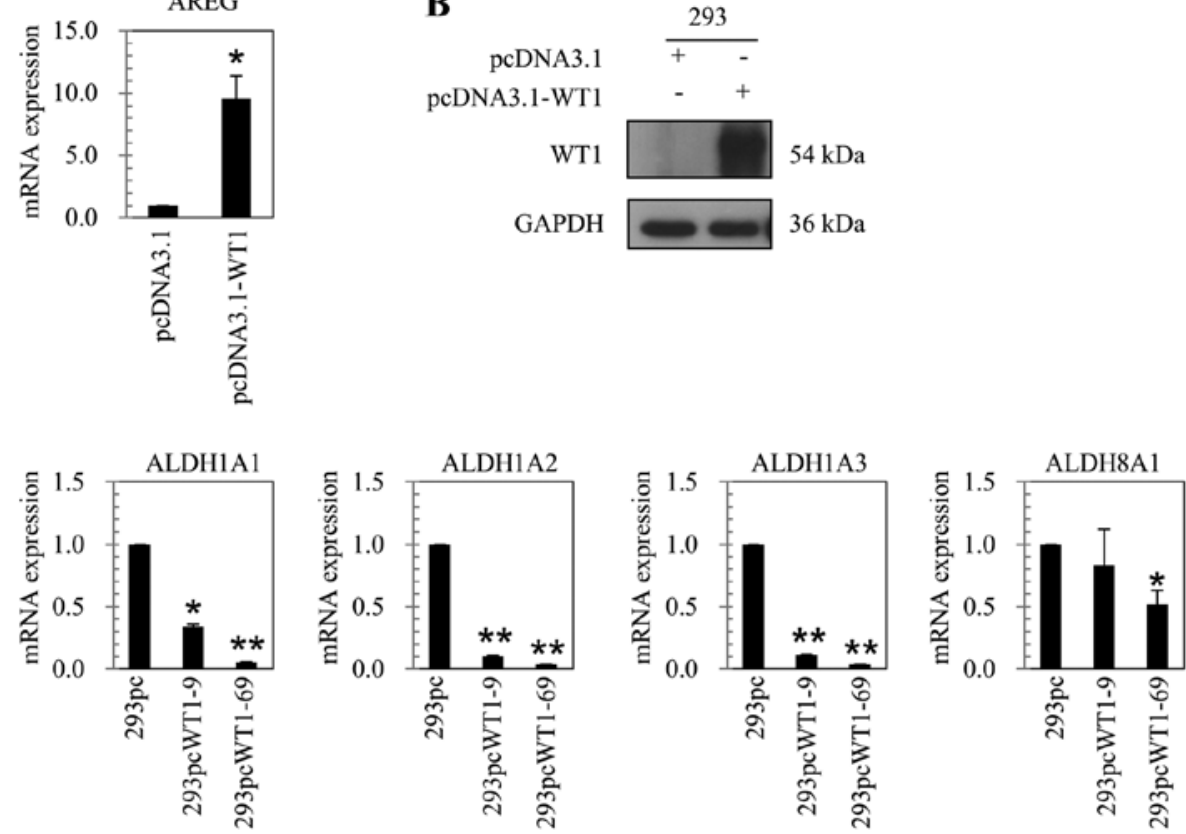

D

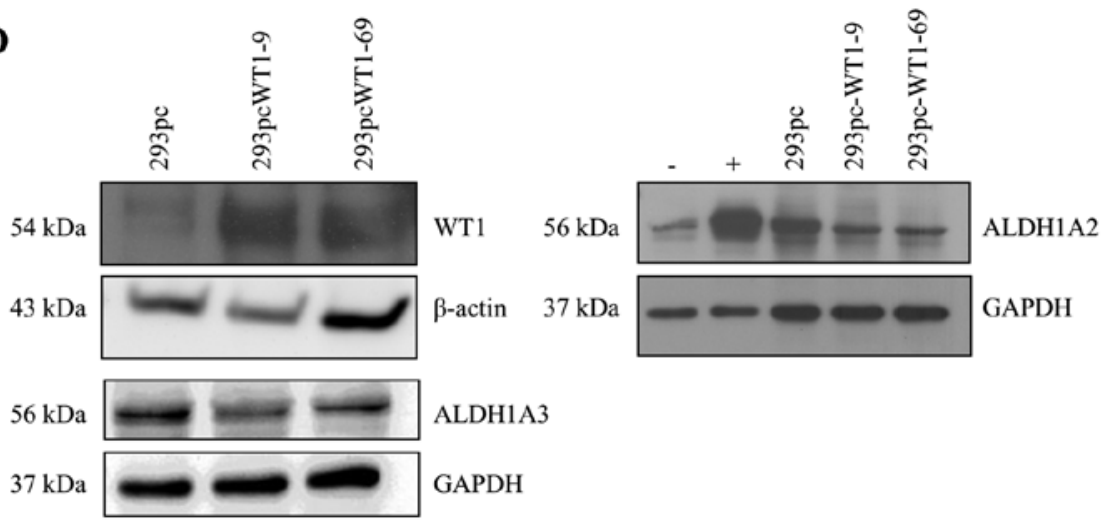

$\mathbf{E}$

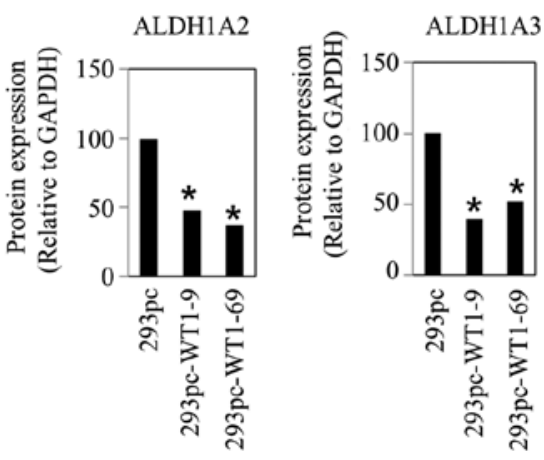

Figure 2. Suppressive effect of WT1 on the expression levels of ALDH1A1, ALDH1A2 and ALDH1A3. (A) WT1 and AREG mRNA expression relative to TBP in 293 cells transiently transfected with pcDNA3.1 or pcDNA3.1-WT1 and harvested 4 days post-transfection, measured by real-time PCR. (B) WT1 protein expression in 293 cells transiently transfected with pcDNA3.1 or pcDNA3.1-WT1, measured by western blot analysis. (C) mRNA expression of WT1, ALDH1A1, ALDH1A2, ALDH1A3, ALDH8A1 relative to house-keeping gene TBP in 293pc, 293pcWT1-9 and 293pcWT1-69 cells, measured by real-time PCR. (D) Protein expression of WT1, ALDH1A2 and ALDH1A3 in 293pc, 293pcWT1-9 and 293pcWT1-69 cells, measured by western blot analysis. $\beta$-actin and GAPDH are used as loading control. (E) Semi-quantitative measurement of ALDH1A2 and ALDH1A3 protein expression in (D) using ImageJ. Numbers on bars show the relative expression value of ALDH1A2 and ALDH1A3 proteins. 293pcWT1-9 and 293pcWT1-69 cells are clones of cell lines from 293 cells stably transfected with pcDNA3.1-WT1 vector. 293pc is a cell line from 293 cells stably transfected with pcDNA3.1 negative control vector. RT-qPCR data are expressed as fold changes. Results are representative of 3 separate experiments. Error bars show the range of duplicate measurements; primer sequences are shown in Table I. +, ALDH1A2 protein positive control by transfection of mammalian expression vector pReceiver-M67-ALDH1A2 to 293 cells. -, ALDH1A2 protein negative control by transfection of pReceiver-M67 empty vector. ALDH1A1, aldehyde dehydrogenase 1 family, member A1. ${ }^{*} \mathrm{P}<0.05,{ }^{* *} \mathrm{P}<0.01$ and ${ }^{* * * *} \mathrm{P}<0.001$, compared with their respective controls, calculated using the Student's t-test.

the control cell line, 293pc (Fig. 2C). The suppression fold changes in the 293pcWT1-9 and 293pcWT1-69 cells compared to those of 293pc cells were as follows: ALDHIAI (0.34- and 0.06 -fold), ALDH1A2 (0.10- and 0.04-fold), ALDH1A3 (0.11and 0.04-fold) and ALDH8Al (0.83- and 0.52-fold) (Fig. 2C).

In the 293 cells, the ALDHIAI and ALDH8A1 mRNA expression levels were very low and their proteins were not detectable by western blot analysis. Therefore, we focused on the measurement of ALDH1A2 and ALDH1A3 protein levels. Western blot analysis revealed that when WT1 protein was upregulated in the 293pcWT1-9 and 293pcWT1-69 cells, the protein expression levles of both $A L D H 1 A 2$ and $A L D H 1 A 3$ were suppressed, compared to the level of the control cell line, 293pc (Fig. 2D and E).
Although WT1 mRNA expression was increased 46.3- and 85.9-fold in the 293pcWT1-9 and 293pcWT1-69 cells, the increase in WT1 protein expression was not proportionate with the mRNA expression. According to the semi-quantificaton of the results of western blot analysis using ImageJ software, the increase in WT1 protein expression was approximately 5.54- and 2.10-fold in the 293pcWT1-9 and 293pcWT1-69 cells, compared to the 293pc cells. Thus, the overexpression of WT1 in the stable lines, 293pcWT1-9 and 293pcWT1-69, was moderate.

Conversion of all-trans retinal to atRA is significantly inhibited by WT1. To determine whether WT1 may have an effect on all-trans retinal to atRA conversion in the cells, HPLC was performed. The substrate all-trans retinal at a 

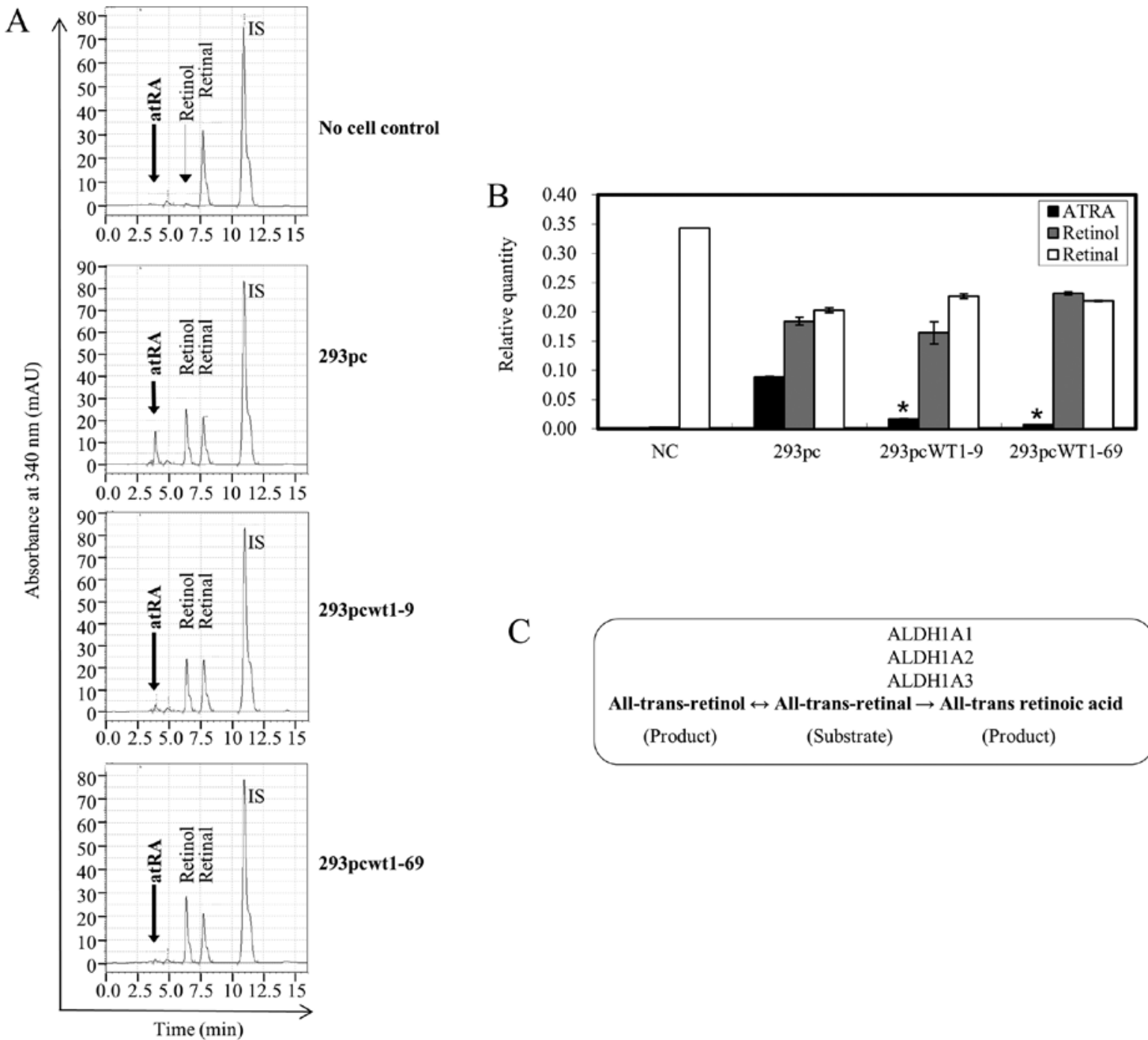

Figure 3. WT1 blocks the conversion of all-trans retinal to all-trans retinoic acid (atRA) analyzed by HPLC. (A) The substrate all-trans retinal at a final concentration of $10 \mu \mathrm{mol} / 1$ was incubated for $4 \mathrm{~h}$ with no cell control, 293pc control cell line, and WT1 expressing cell lines 293pcWT1-9 and 293pcWT1-69, respectively. The substrate and resulting products were extracted and analyzed using HPLC. The retention time of atRA, all-trans retinol, all-trans retinal and internal standard (IS) retinyl acetate are $3.9,6.4,7.7$ and $10.9 \mathrm{~min}$, respectively. Results are representative of 3 separate experiments. (B) Quantitative comparison of atRA, all-trans retinol and all-trans retinal relative to IS according to area of each peak as shown in (A). Error bars show the range of two separate experiments. "P<0.05 vs. ATRA level of the $293 \mathrm{pc}$ cells group, calculated using the Student's t-test. (C) atRA synthesis pathway and enzymes responsible for the all-trans retinal to atRA conversion.

final concentration of $10 \mu \mathrm{mol} / 1$ was incubated for $4 \mathrm{~h}$ with the negative control (with only culture medium but without cells), 293pc, 293pcWT1-9 and 293pcWT1-69, respectively. The resulting products and remaining substrate in the culture media and cell lysates were extracted with hexane and subjected to HPLC analysis. The result revealed that all-trans retinal was efficiently converted into all-trans retinol and atRA in the 293pc cells at $4 \mathrm{~h}$ post-incubation (Fig. 3A and C). The conversion of all-trans retinal into atRA was significantly inhibited (Fig. 3A), as shown by the relative quantities of atRA, $0.0169(19.1 \%)$ and $0.0074(8.4 \%)$ in the 293pcWT1-9 and 293pcWT1-69 cells, compared to $0.0884(100 \%)$ in the 293pc cells, respectively (Fig. 3B). The all-trans retinal into all-trans retinol conversion in the 293pcWT1-9 and 293pcWT1-69 cells was not significantly altered compared to that in the 293pc cells. In the no cell negative control, there was no obvious reduction or oxidation in the substrate alltrans retinal (Fig. 3A and B).
Analysis of ALDH1A1, ALDH1A2 and ALDH1A3 promoter $D N A C p G$ methylation. Previous studies have shown that WT1 can suppress gene expression via an increase in DNA methylation (55) and other epigenetic mechanisms $(28,56)$. Promoter hypermethylation has been observed in $A L D H 1 A 2$ (57) and $A L D H 1 A 3$ (58-60). These observations led us to hypothesize that the WT1 regulation of $A L D H 1 A 2$ and $A L D H 1 A 3$ may be related to changes in promoter methylation. Therefore, we performed bisulfite sequencing on the promoter regions of ALDHIAl, $A L D H 1 A 2$ and ALDH1A3 in the 293pc, 293pcWT1-9 and 293pcWT1-69 cells. The results revealed that in the core region of the ALDH1A2 promoter (ALDH1A2 BS1, BS2 and BS3), CpGs were not heavily methylated in the 293pc, 293pcWT1-9 and 293pcWT1-69 cells (Fig. 4). This also applied to ALDH1A3, whose core promoter region (ALDH1A3 BS2.1, BS2.2) also showed very little methylation (Fig. 4). the $A L D H 1 A 1$ promoter is not $\mathrm{GC}$ rich and contains no $\mathrm{CpG}$ island. However, a previous study demonstrated that DNA methylation can also silence 


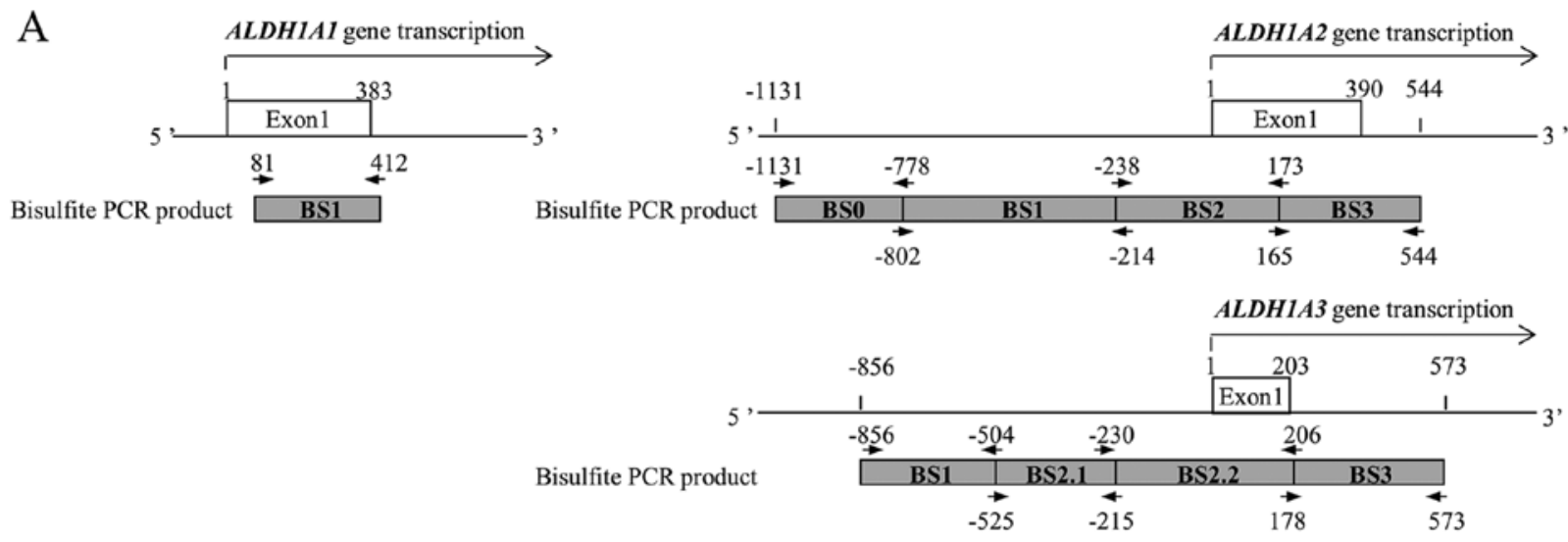

$\mathrm{B}$

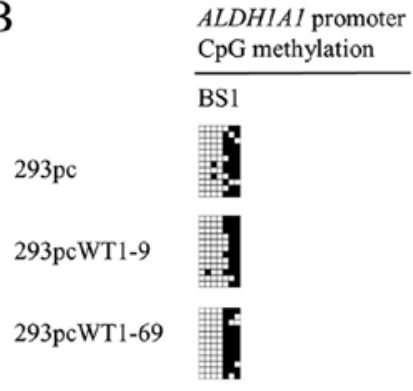

ALDHIA2 promoter CpG methylation

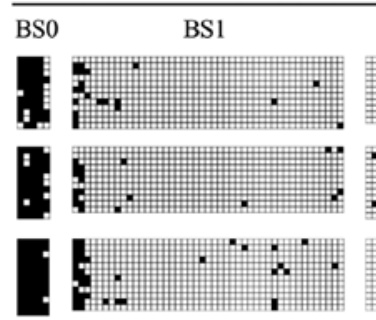

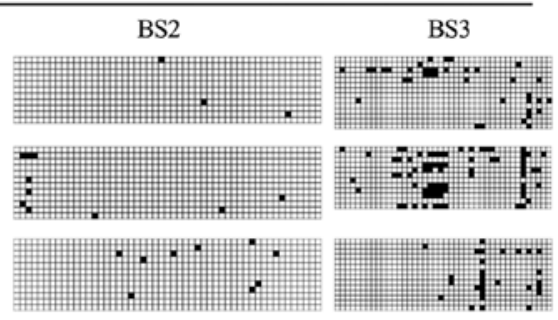

ALDH1A3 promoter CpG methylation

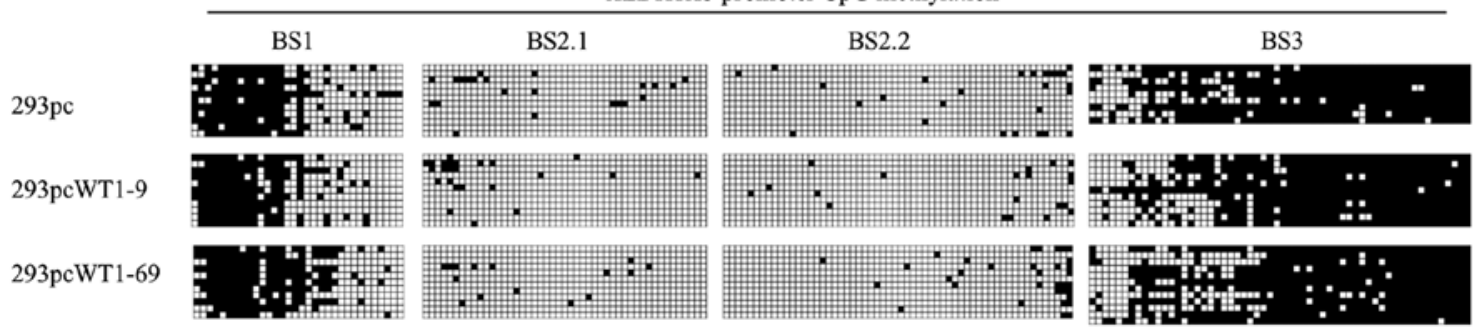

Figure 4. CpG methylation of promoters of ALDH1A1, ALDH1A2 and ALDH1A3 in 293pc, 293pcWT1-9 and 293pcWT1-69 cells analyzed by bisulfite sequencing. (A) Schematic diagrams of $A L D H 1 A 1, A L D H 1 A 2$ and $A L D H 1 A 3$ genes, bisulfite PCR product positions and their labels. Numbers represent base pair (bp) numbers starting from the transcription start site. Unfilled rectangles represent exons. Rectangles filled with gray represent bisulfite PCR fragments. Short arrows indicate bisulfite PCR primers. (B) DNA CpG methylation on ALDH1A1, ALDH1A2 and ALDH1A3 promoters in 293pc, 293pcWT1-9 and 293pcWT1-69 cells was measured by bisulfite sequencing. Primer sequences for bisulfite PCR are shown in Table II. Filled squares represent methylated CpG dinucleotides and open squares represent unmethylated CpGs. ALDH1A1, aldehyde dehydrogenase 1 family, member A1.

non-CpG island promoter (61); therefore we still included a region of the $A L D H 1 A 1$ promoter (ALDH1A1 BS1) containing more $\mathrm{CpGs}$ (7 CpGs) than other regions of the promoter for $\mathrm{CpG}$ methylation analysis. The results revealed that $4 \mathrm{CpGs}$ at $5^{\prime}$ end were less methylated, and $3 \mathrm{CpGs}$ at $3^{\prime}$ end is heavily methylated (Fig. 4B). However, there were no marked changes in CpG methylation in the promoters of ALDH1A1, ALDH1A2 and $A L D H 1 A 3$ in the 293pcWT1-9 and 293pcWT1-69 cells, compared to the 293pc cells (Fig. 4B).

ALDH1A1 is upregulated by treatment with AZA. We then wished to further determine whether DNA methylation may indeed not be related to $A L D H 1 A 1, A L D H 1 A 2$ and $A L D H 1 A 3$ suppression by WT1. We treated the 293pcWT1-9 and 293pcWT1-69 cells with $5 \mu \mathrm{mol} / 1 \mathrm{AZA}$ or negative control DMSO for 48 and $72 \mathrm{~h}$. The results of RT-qPCR revealed that in the 293pcWT1-9 cells treated with AZA, ALDH1A1 mRNA expression was upregulated 2.66- and 5.76-fold at 48 and $72 \mathrm{~h}$, compared to that in the DMSO control, respectively (Fig. 5A). In the 293pcWT1-69 cells treated with AZA, ALDH1A1 mRNA expression was upregulated 1.42- and 2.63-fold at 48 and $72 \mathrm{~h}$, compared to the DMSO control, respectively (Fig. 5B). However, treatment with $5 \mu \mathrm{mol} / 1 \mathrm{AZA}$ for 48 and $72 \mathrm{~h}$ had little effect on the expression of WT1, ALDH1A2 and ALDH1A3 in both the 293pcWT1-9 and 293pcWT1-69 cells (an upregulation of $>2$-fold was considered significant) (Fig. 5).

Upregulation of ALDHIAl by HDAC inhibitors. HDACs are enzymes that regulate chromatin architecture and gene expression by the removal of acetyl groups from histone tails. Previous studies have indicated that HDACs are potent regulators in kidney development $(38,39)$ and are involved in the regulation of retinoic acid signaling (62). Therefore, we examined whether HDAC inhibitors may alleviate the suppression of $A L D H 1 A 1, A L D H 1 A 2$ and $A L D H 1 A 3$ by WT1. The results of RT-qPCR revealed that $A L D H 1 A 1$ was markedly upregulated 

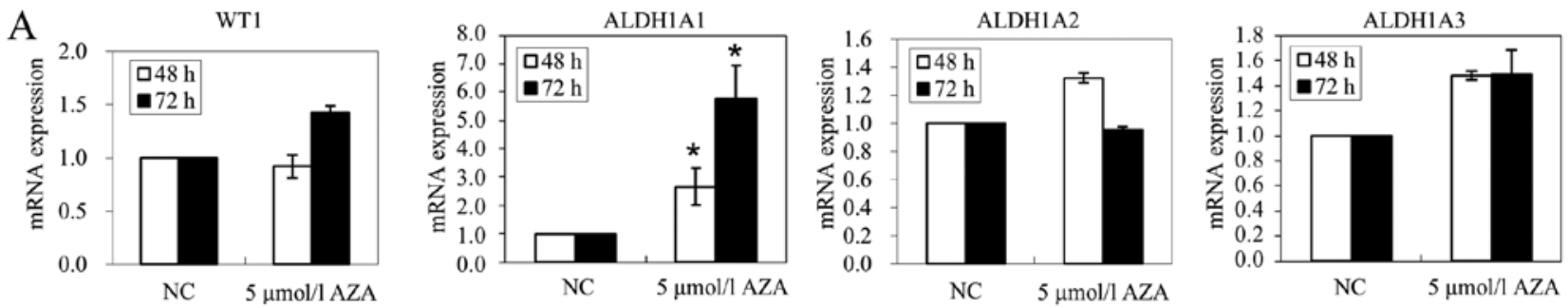

293pcWT1-9
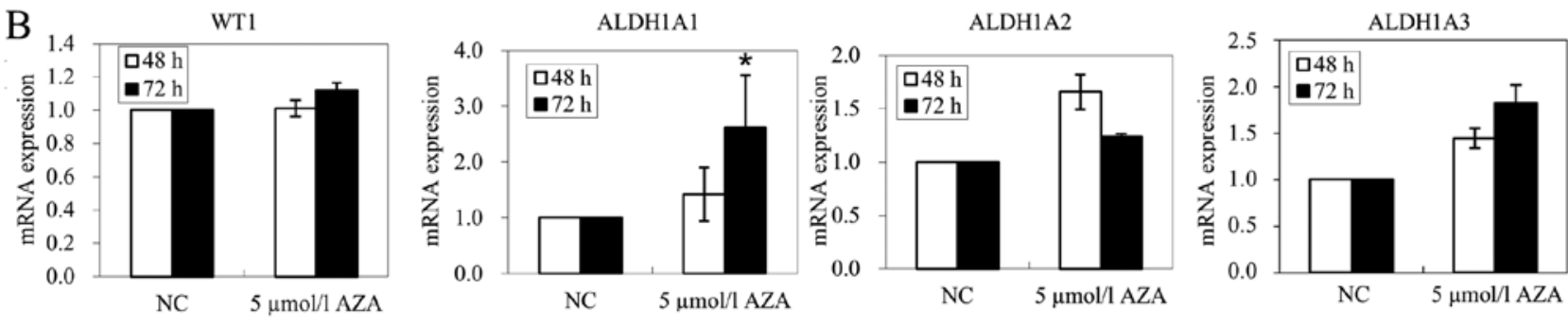

293pcWT1-69

Figure 5. Effects of AZA on the expression of ALDH1A1, ALDH1A2 and ALDH1A3. mRNA expression of WT1, ALDH1A1, ALDH1A2 and ALDH1A3 in 293pcWT1-9 cells (A) and 293pcWT1-69 cells (B) treated with $5 \mu \mathrm{mol} / 1$ AZA or negative control (NC) DMSO for 48 and $72 \mathrm{~h}$, measured by RT-qPCR. All RT-qPCR data are relative to the housekeeping gene, TBP. Data are expressed as fold change relative to DMSO control cells. Results are representative of 3 separate experiments. Error bars show the range of duplicate measurements; primer sequences are shown in Table I. ALDH1A1, aldehyde dehydrogenase 1 family, member A1; AZA, 5-Aza-2'-deoxycytidine. "P<0.05 compared with negative controls, determined by the Student's t-test.

A

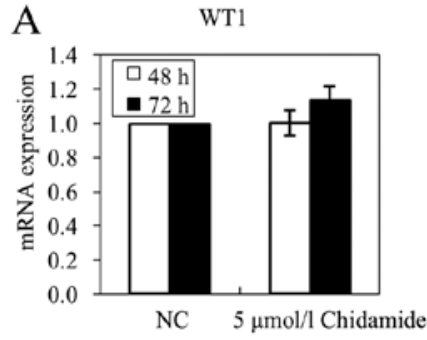

ALDH1A1

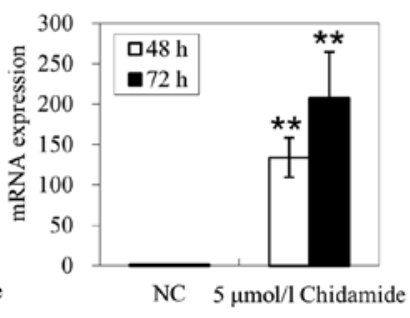

ALDH1A2

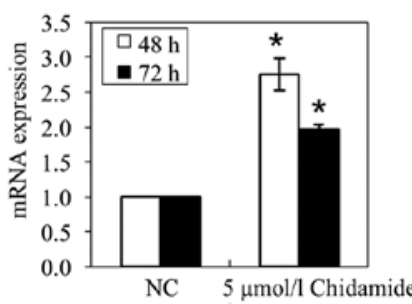

ALDH1A3

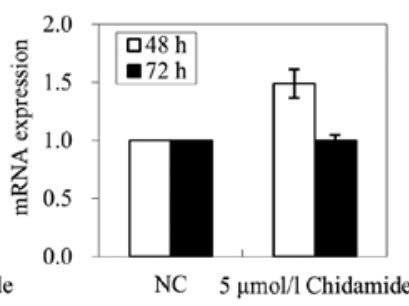

293pcWT1-9

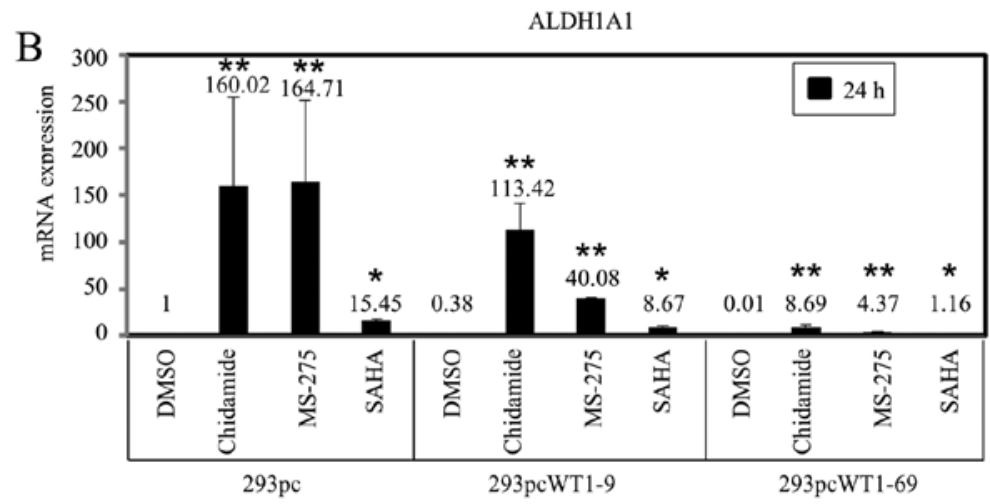

Figure 6. Effects of histone deacetylase (HDAC) inhibitors on $A L D H 1 A 1$ expression. (A) mRNA expression of WT1, ALDH1A1, ALDH1A2 and ALDH1A3 in 293pcWT1-9 cells treated with $5 \mu \mathrm{mol} / 1$ chidamide or negative control (NC) DMSO for 48 and 72 h, measured by real-time PCR. (B) RT-qPCR analysis of ALDH1A1 mRNA expression in 293pc, 293pcWT1-9 and 293pcWT1-69 cells, which were treated with DMSO, chidamide, MS-275 and SAHA (5 $\mu$ mol/1 each) for $24 \mathrm{~h}$, respectively. All RT-qPCR data are relative to the housekeeping gene, TBP. Data are expressed as fold change relative to gene expression in negative control treated with DMSO. Numbers on each bar shows the average fold change. Results are representative of 3 separate experiments. Error bars show the range of duplicate measurements; primer sequences are shown in Table I. ALDH1A1, aldehyde dehydrogenase 1 family, member A1. ${ }^{*}<0.05$ and ${ }^{* *} \mathrm{P}<0.01$, compared with their respective controls, calculated using the Student's t-test.

142- and 200-fold in the 293pcWT1-9 cells treated with $5 \mu \mathrm{mol} / 1$ of the HDAC inhibitor, chidamide, for 48 and $72 \mathrm{~h}$, compared to that in the DMSO control, respectively (Fig. 6A). However, chidamide had a minor effect on the gene expression 
of $A L D H 1 A 2$ and $A L D H 1 A 3$, in which the minor upregulation of $A L D H 1 A 2$ (2.75-fold) and $A L D H 1 A 3$ (1.49-fold) in 293pcWT1-9 and 293pcWT1-69 at $48 \mathrm{~h}$ compared to that in $293 \mathrm{pc}$, was reversed to 1.97 - and 1 -fold at $72 \mathrm{~h}$, respectively (Fig. 6A).

We then examined whether the other HDAC inhibitors, MS-275 and SAHA, may have an effect on the regulation of ALDHIAl expression. Indeed, MS-275 and SAHA also strongly activated $A L D H 1 A 1$ expression in the 293pc, 293pcWT1-9 and 293pcWT1-69 cells, compared to that of each cell line treated with DMSO, respectively (Fig. 6B).

\section{Discussion}

In this study, we demonstrated that WT1 suppressed $A L D H 1 A 1$, $A L D H 1 A 2$ and $A L D H 1 A 3$ expression, leading to a marked reduction in retinoic acid synthesis. The suppression of $A L D H 1 A 1$, $A L D H 1 A 2$ and $A L D H 1 A 3$ by WT1 was not related to promoter DNA CpG methylation. Furthermore, HDAC inhibitors and AZA alleviated the suppression of ALDH1A1 by WT1.

Previous studies have been more interested in looking at the presence or upregulation of retinoic acid synthetic enzymes, probably due to the indispensible roles of atRA signaling in renal development. However, the limitation of atRA concentrations at certain segment during renal development may also be important, as the excess of atRA is teratogenic and can cause hypoplastic and polycystic kidney. Gradient RA production has been observed to be required in development of paraxial mesoderm (21), intestine, hindbrain (20) and limb (22). The uneven distribution of retinoic acid can be achieved by the expression of atRA degradation CYP26 enzymes $(18,19)$. In the present study, we provide evidence to indicate that WTI overexpression suppresses the expression of $A L D H 1 A 1$, $A L D H 1 A 2$ and $A L D H 1 A 3$ in 293 cells in vitro, and present data to indicate that HDACs suppress $A L D H 1 A 1$, proposing an additional candidate mechanism that may limit atRA overproduction.

The result that WT1 can suppress ALDH1A2 expression in 293 cells is in contrast to that of previous studies, showing that Wt1 upregulates Aldhla2 in the embryonic epicardium (36) and coelomic cells lining the embryonic liver (35). The suppression of $A L D H 1 A 1$ by WT1 is also in contrast to the findings of a previous study, showing that the knockout of Wtl leads to the downregulation of Aldhlal in the developing gonad (37). These data suggest that $A L D H 1 A 2$ and $A L D H 1 A 1$ regulation by WT1 is cell context-dependent. It is not known whether WT1 cofactors or 'chromatin flip-flop' effect may be involved in the difference of WT1 regulation of ALDH1A2 and ALDH1A1.

It has been shown that WT1 directly upregulated $A L D H 1 A 2$ expression (36), but the biochemical net output of atRA production regulated by WT1 has not been shown. In this study, we demonstrate that WT1 stable expression leads to the suppression of retinal to atRA conversion demonstrated by HPLC. To the best of our knowledge, this is the first direct evidence showing that WT1 can regulate atRA generation.

We did not find any significant changes in the methylation status of $A L D H 1 A 2$ and ALDH1A3 promoters in the 293 cells transfected with WT1. However, we observed that $A L D H 1 A 3$ promoter was more methylated in regions flanking its core promoter in 293 cells (Fig. 4B), while its core region of promoter was not heavily methylated (Fig. 4B), which is in accordance with its expression state in 293 cells (Fig. 1B and D). Although the promoter methylation of $A L D H 1 A 2$ (57) and $A L D H 1 A 3$ (58-60) occurs in cancers, the WT1 regulation of ALDH1A2 and ALDH1A3 in 293 cells is not dependent on the promoter DNA methylation pathway, suggesting that DNA methylation machinery may not be involved in the control of $A L D H 1 A 2$ and $A L D H 1 A 3$ expression by WT1. This was further examined by AZA treatment, which did not significantly alter $A L D H 1 A 2$ and ALDH1A3 expression in 293pcWT1-9 and 293pcWT1-69 cells (Fig. 5). The ALDH1A1 promoter is not GC rich and has no $\mathrm{CpG}$ island. We demonstrated that ALDH1A1 promoter methylation exhibited little change in WT1-transfected 293 cells (Fig. 4B). However it is intriguing to note that ALDH1A1 expression was upregulated by AZA treatment at 48 and $72 \mathrm{~h}$, suggesting that epigenetic related mechanisms may still be involved in ALDH1A1 expression in 293 cells.

In this study, although we did not find evidence that the WT1 regulation of $A L D H 1 A 1, A L D H 1 A 2$ and $A L D H 1 A 3$ was associated with DNA hypermethylation, we observed that histone deacetylation was a strong regulator of $A L D H 1 A 1$ expression. We also demonstrated that $A L D H 1 A 1$ expression in the 293pcWT1-9 and 293pcWT1-69 cells treated with HDAC inhibitors was higher than that in the cells treated with DMSO control (Fig. 6), suggesting that the suppressive effect of WT1 on ALDHIAl expression can be abrogated by HDAC inhibitors. HDAC inhibitors markedly activated ALDH1A1 expression in 293 cells with or without WT1 stable expression (Fig. 6B), suggesting that a high level of histone deacetylase alone may be a major epigenetic regulator responsible for the very low expression of ALDH1A1 in 293 cells, which may reflect the lack of Aldhlal expression in the developing metanephric mesenchyme cell lineage that finally differentiates into glomerular podocytes. It has been shown that HDAC inhibitors are strong regulators of kidney development and disease $(38,39)$. In a previous study, kidney rudiments treated with the HDAC inhibitors, trichostatin A (TSA), scriptaid or MS-275 exhibited stunted ureteric bud branching (39). HDAC1, HDAC2 and HDAC3 proteins are all expressed in mouse kidneys on embryonic day 17 (E17) and post-natal day 1 (P1) and decline as the mouse matures. HDAC1 and HDAC2 proteins are enriched in less differentiated nephron structures (39). The HDAC3 expression pattern is similar to that of HDAC1 and HDAC2, except that it is also localized in glomerular podocytes $(39,63,64)$. Proteins of acetylated histone 3 and acetylated histone 4 are expressed in mouse kidneys on E17, P1, P20 and adults (39). These data suggest that HDACs play a key role in renal development. Of note, the inhibition of HDACs by TSA in articular chondrocytes cells derived from new born rats has been shown to increase the retinoic acid signal, which suppresses Sox9 transcription (62). It is not known in the fetal kidney context, whether HDAC inhibitors may also result in an increase in RA signaling, which may due to $A L D H 1 A 1$ upregulation and more production of atRA. Future studies need to address whether ALDH1Al may be a crucial target that mediates the roles of HDACs and its inhibitors in kidney development and disease.

The regulation of $A L D H 1 A 2$ in fetal kidney cells is complex and is very likely to involve more than one regulatory factor. For example, the transient and strong expression of $A L D H 1 A 2$ 
in the visceral layer of the glomerulus of the stage III nephron may due to the effect of other unknown transcription factors or the activation effect of WT1. The result that $A L D H 1 A 2$ was suppressed by WT1 in the 293 cells may be relevant to the downregulation of Aldhla2 in podocytes of the stage IV nephron, in which $W t 1$ is progressively upregulated.

\section{Acknowledgements}

We would like to thank Dr Herman Yeger (Hospital for Sick Children, Toronto, Canada) for allowing us to use the WiT49 cell line. We would also like to thank Drs Mei-Hong LI and Fernando Ferrer (Center for Vascular Biology, University of Connecticut Health Center, Farmington, CT, USA) for shipping us this cell line. This study was funded by the National Natural Science Foundation of China (no. 31100943), the Shenzhen City Science and Technology Project (no. 201102136) and the Shenzhen Nanshan Science and Technology Research Funds (nos. 2010012 and 2014009).

\section{References}

1. Duester G: Retinoic acid synthesis and signaling during early organogenesis. Cell 134: 921-931, 2008.

2. Gudas LJ: Emerging roles for retinoids in regeneration and differentiation in normal and disease states. Biochim Biophys Acta 1821: 213-221, 2012

3. Tang XH and Gudas LJ: Retinoids, retinoic acid receptors, and cancer. Annu Rev Pathol 6: 345-364, 2011.

4. Dollé P: Developmental expression of retinoic acid receptors (RARs). Nucl Recept Signal 7: e006, 2009.

5. Napoli JL: Physiological insights into all-trans-retinoic acid biosynthesis. Biochim Biophys Acta 1821: 152-167, 2012.

6. Fan X, Molotkov A, Manabe S, Donmoyer CM, Deltour L, Foglio MH, Cuenca AE, Blaner WS, Lipton SA and Duester G: Targeted disruption of Aldh1a1 (Raldh1) provides evidence for a complex mechanism of retinoic acid synthesis in the developing retina. Mol Cell Biol 23: 4637-4648, 2003.

7. Zhao D, McCaffery P, Ivins KJ, Neve RL, Hogan P, Chin WW and Dräger UC: Molecular identification of a major retinoic-acidsynthesizing enzyme, a retinaldehyde-specific dehydrogenase. Eur J Biochem 240: 15-22, 1996.

8. Wang X, Penzes P and Napoli JL: Cloning of a cDNA encoding an aldehyde dehydrogenase and its expression in Escherichia coli. Recognition of retinal as substrate. J Biol Chem 271: 16288-16293, 1996.

9. Sima A, Parisotto M, Mader S and Bhat PV: Kinetic characterization of recombinant mouse retinal dehydrogenase types 3 and 4 for retinal substrates. Biochim Biophys Acta 1790: 1660-1664: 2009.

10. Grün F, Hirose Y, Kawauchi S, Ogura T and Umesono K: Aldehyde dehydrogenase 6, a cytosolic retinaldehyde dehydrogenase prominently expressed in sensory neuroepithelia during development. J Biol Chem 275: 41210-41218, 2000.

11. Dressler GR: Advances in early kidney specification, development and patterning. Development 136: 3863-3874, 2009.

12. Davidson A: Mouse kidney development. In: StemBook. 2008.

13. Mendelsohn C, Batourina E, Fung S, Gilbert T and Dodd J: Stromal cells mediate retinoid-dependent functions essential for renal development. Development 126: 1139-1148, 1999.

14. Rosselot C, Spraggon L, Chia I, Batourina E, Riccio P, Lu B, Niederreither K, Dolle P, Duester G, Chambon P, et al Non-cell-autonomous retinoid signaling is crucial for renal development. Development 137: 283-292, 2010.

15. Batourina E, Gim S, Bello N, Shy M, Clagett-Dame M, Srinivas S, Costantini F and Mendelsohn C: Vitamin A controls epithelial/ mesenchymal interactions through Ret expression. Nat Genet 27: 74-78, 2001.

16. Lee LM, Leung CY, Tang WW, Choi HL, Leung YC, McCaffery PJ, Wang CC, Woolf AS and Shum AS: A paradoxical teratogenic mechanism for retinoic acid. Proc Natl Acad Sci USA 109: 13668-13673, 2012.
17. Wingert RA, Selleck R, Yu J, Song HD, Chen Z, Song A, Zhou Y, Thisse B, Thisse C, McMahon AP, et al: The cdx genes and retinoic acid control the positioning and segmentation of the zebrafish pronephros. PLoS Genet 3: 1922-1938, 2007.

18. Abu-Abed S, Dollé P, Metzger D, Beckett B, Chambon P and Petkovich M: The retinoic acid-metabolizing enzyme, CYP26A1, is essential for normal hindbrain patterning, vertebral identity, and development of posterior structures. Genes Dev 15: 226-240, 2001.

19. Hernandez RE, Putzke AP, Myers JP, Margaretha L and Moens CB: Cyp26 enzymes generate the retinoic acid response pattern necessary for hindbrain development. Development 134: 177-187, 2007.

20. Godsave SF, Koster CH, Getahun A, Mathu M, Hooiveld M, van der Wees J, Hendriks J and Durston AJ: Graded retinoid responses in the developing hindbrain. Dev Dyn 213: 39-49, 1998.

21. Rhinn M and Dollé P: Retinoic acid signalling during development. Development 139: 843-858, 2012.

22. Yashiro K, Zhao X, Uehara M, Yamashita K, Nishijima M, Nishino J, Saijoh Y, Sakai Y and Hamada H: Regulation of retinoic acid distribution is required for proximodistal patterning and outgrowth of the developing mouse limb. Dev Cell 6: 411-422, 2004

23. Haselbeck RJ, Hoffmann I and Duester G: Distinct functions for Aldh1 and Raldh2 in the control of ligand production for embryonic retinoid signaling pathways. Dev Genet 25: 353-364, 1999.

24. Niederreither K, Fraulob V, Garnier JM, Chambon P and Dollé P: Differential expression of retinoic acid-synthesizing (RALDH) enzymes during fetal development and organ differentiation in the mouse. Mech Dev 110: 165-171, 2002.

25. Marlier A and Gilbert T: Expression of retinoic acid-synthesizing and -metabolizing enzymes during nephrogenesis in the rat. Gene Expr Patterns 5: 179-185, 2004.

26. Hohenstein P and Hastie ND: The many facets of the Wilms tumour gene, WT1. Hum Mol Genet 15: R196-R201, 2006.

27. Roberts SGE: Transcriptional regulation by WT1 in development. Curr Opin Genet Dev 15: 542-547, 2005.

28. Essafi A, Webb A, Berry RL, Slight J, Burn SF, Spraggon L, Velecela V, Martinez-Estrada OM, Wiltshire JH, Roberts SG, et al: A wt1-controlled chromatin switching mechanism underpins tissue-specific wnt4 activation and repression. Dev Cell 21: 559-574, 2011.

29. Haber DA, Sohn RL, Buckler AJ, Pelletier J, Call KM and Housman DE: Alternative splicing and genomic structure of the Wilms tumor gene WT1. Proc Natl Acad Sci USA 88: 9618-9622, 1991.

30. Larsson SH, Charlieu JP, Miyagawa K, Engelkamp D, Rassoulzadegan M, Ross A, Cuzin F, van Heyningen V and Hastie ND: Subnuclear localization of WT1 in splicing or transcription factor domains is regulated by alternative splicing. Cell 81: 391-401, 1995.

31. Armstrong JF, Pritchard-Jones K, Bickmore WA, Hastie ND and Bard JB: The expression of the Wilms' tumour gene, WT1, in the developing mammalian embryo. Mech Dev 40: 85-97, 1993.

32. Pritchard-Jones K, Fleming S, Davidson D, Bickmore W, Porteous D, Gosden C, Bard J, Buckler A, Pelletier J, Housman D, et al: The candidate Wilms' tumour gene is involved in genitourinary development. Nature 346: 194-197, 1990.

33. Kreidberg JA, Sariola H, Loring JM, Maeda M, Pelletier J, Housman D and Jaenisch R: WT-1 is required for early kidney development. Cell 74: 679-691, 1993.

34. von Gise A, Zhou B, Honor LB, Ma Q, Petryk A and Pu WT: WT1 regulates epicardial epithelial to mesenchymal transition through $\beta$-catenin and retinoic acid signaling pathways. Dev Biol 356: 421-431, 2011.

35. Norden J, Grieskamp T, Lausch E, van Wijk B, van den Hoff MJ, Englert C, Petry M, Mommersteeg MT, Christoffels VM, Niederreither $\mathrm{K}$, et al: $\mathrm{Wt} 1$ and retinoic acid signaling in the subcoelomic mesenchyme control the development of the pleuropericardial membranes and the sinus horns. Circ Res 106: $1212-1220,2010$

36. Guadix JA, Ruiz-Villalba A, Lettice L, Velecela V, Muñoz-Chápuli R, Hastie ND, Pérez-Pomares JM and MartínezEstrada OM: Wt1 controls retinoic acid signalling in embryonic epicardium through transcriptional activation of Raldh2. Development 138: 1093-1097, 2011.

37. Klattig J, Sierig R, Kruspe D, Makki MS and Englert C: WT1-mediated gene regulation in early urogenital ridge development. Sex Dev 1: 238-254, 2007. 
38. Brilli LL, Swanhart LM, de Caestecker MP and Hukriede NA: HDAC inhibitors in kidney development and disease. Pediatr Nephrol 28: 1909-1921, 2013.

39. Chen S, Bellew C, Yao X, Stefkova J, Dipp S, Saifudeen Z, Bachvarov D and El-Dahr SS: Histone deacetylase (HDAC) activity is critical for embryonic kidney gene expression, growth, and differentiation. J Biol Chem 286: 32775-32789, 2011.

40. Hu E, Dul E, Sung CM, Chen Z, Kirkpatrick R, Zhang GF, Johanson K, Liu R, Lago A, Hofmann G, et al: Identification of novel isoform-selective inhibitors within class I histone deacetylases. J Pharmacol Exp Ther 307: 720-728, 2003.

41. Liu L, Chen B, Qin S, Li S, He X, Qiu S, Zhao W and Zhao H: A novel histone deacetylase inhibitor Chidamide induces apoptosis of human colon cancer cells. Biochem Biophys Res Commun 392: 190-195, 2010.

42. Khan $\mathrm{O}$ and La Thangue NB: HDAC inhibitors in cancer biology: Emerging mechanisms and clinical applications. Immunol Cell Biol 90: 85-94, 2012.

43. Graham FL, Smiley J, Russell WC and Nairn R: Characteristics of a human cell line transformed by DNA from human adenovirus type 5. J Gen Virol 36: 59-74, 1977.

44. Alami J, Williams BR and Yeger H: Derivation and characterization of a Wilms' tumour cell line, WiT 49. Int J Cancer 107: 365-374, 2003

45. Wang C, Kane MA and Napoli JL: Multiple retinol and retinal dehydrogenases catalyze all-trans-retinoic acid biosynthesis in astrocytes. J Biol Chem 286: 6542-6553, 2011.

46. Kane MA, Chen N, Sparks S and Napoli JL: Quantification of endogenous retinoic acid in limited biological samples by LC/MS/MS. Biochem J 388: 363-369, 2005.

47. Huang DY and Ichikawa Y: Purification and characterization of a novel cytosolic NADP $(\mathrm{H})$-dependent retinol oxidoreductase from rabbit liver. Biochim Biophys Acta 1338: 47-59, 1997.

48. Yang YM, Huang DY, Liu GF, Zhong JC, Du K, Li YF and Song XH: Effects of 2,3,7,8-tetrachlorodibenzo-p-dioxin on vitamin A metabolism in mice. J Biochem Mol Toxicol 19: 327-335, 2005.

49. Li LC and Dahiya R: MethPrimer: Designing primers for methylation PCRs. Bioinformatics 18: 1427-1431, 2002.

50. Carr IM, Valleley EM, Cordery SF, Markham AF and Bonthron DT: Sequence analysis and editing for bisulphite genomic sequencing projects. Nucleic Acids Res 35: e79, 2007.

51. Schneider CA, Rasband WS and Eliceiri KW: NIH Image to ImageJ: 25 years of image analysis. Nat Methods 9: 671-675, 2012.

52. Brown KW and Malik KT: The molecular biology of Wilms tumour. Expert Rev Mol Med 2001: 1-16, 2001.

53. Lin M, Zhang M, Abraham M, Smith SM and Napoli JL: Mouse retinal dehydrogenase 4 (RALDH4), molecular cloning, cellular expression, and activity in 9-cis-retinoic acid biosynthesis in intact cells. J Biol Chem 278: 9856-9861, 2003.
54. Lee SB, Huang K, Palmer R, Truong VB, Herzlinger D, Kolquist KA, Wong J, Paulding C, Yoon SK, Gerald W, et al: The Wilms tumor suppressor WT1 encodes a transcriptional activator of amphiregulin. Cell 98: 663-673, 1999.

55. Szemes M, Dallosso AR, Melegh Z, Curry T, Li Y, Rivers C, Uney J, Mägdefrau AS, Schwiderski K, Park JH, et al: Control of epigenetic states by WT1 via regulation of de novo DNA methyltransferase 3A. Hum Mol Genet 22: 74-83, 2013.

56. Xu B, Zeng DQ, Wu Y, Zheng R, Gu L, Lin X, Hua X and Jin GH: Tumor suppressor menin represses paired box gene 2 expression via Wilms tumor suppressor protein-polycomb group complex. J Biol Chem 286: 13937-13944, 2011.

57. Kim H, Lapointe J, Kaygusuz G, Ong DE, Li C, van de Rijn M, Brooks JD and Pollack JR: The retinoic acid synthesis gene ALDH1a2 is a candidate tumor suppressor in prostate cancer. Cancer Res 65: 8118-8124, 2005.

58. Zhang W, Yan W, You G, Bao Z, Wang Y, Liu Y, You Y and Jiang T: Genome-wide DNA methylation profiling identifies ALDH1A3 promoter methylation as a prognostic predictor in G-CIMP- primary glioblastoma. Cancer Lett 328: 120-125, 2013

59. Kim YJ, Yoon HY, Kim JS, Kang HW, Min BD, Kim SK, Ha YS, Kim IY, Ryu KH, Lee SC, et al: HOXA9, ISL1 and ALDH1A3 methylation patterns as prognostic markers for nonmuscle invasive bladder cancer: Array-based DNA methylation and expression profiling. Int J Cancer 133: 1135-1142, 2013.

60. Shames DS, Girard L, Gao B, Sato M, Lewis CM, Shivapurkar N, Jiang A, Perou CM, Kim YH, Pollack JR, et al: A genome-wide screen for promoter methylation in lung cancer identifies novel methylation markers for multiple malignancies. PLoS Med 3: e486, 2006.

61. Han H, Cortez CC, Yang X, Nichols PW, Jones PA and Liang G: DNA methylation directly silences genes with non-CpG island promoters and establishes a nucleosome occupied promoter. Hum Mol Genet 20: 4299-4310, 2011.

62. Weston AD, Chandraratna RA, Torchia J and Underhill TM Requirement for RAR-mediated gene repression in skeletal progenitor differentiation. J Cell Biol 158: 39-51, 2002.

63. Sharma M, Brantley JG, Vassmer D, Chaturvedi G, Baas J and Vanden Heuvel GB: The homeodomain protein Cux1 interacts with Grg4 to repress p27 kip1 expression during kidney development. Gene 439: 87-94, 2009.

64. Chen S and El-Dahr SS: Histone deacetylases in kidney development: Implications for disease and therapy. Pediatr Nephrol 28: 689-698, 2013. 